\title{
Basic oral care for hematology-oncology patients and hematopoietic stem cell transplantation recipients: a position paper from the joint task force of the Multinational Association of Supportive Care in Cancer/International Society of Oral Oncology (MASCC/ISOO) and the European Society for Blood and Marrow Transplantation (EBMT)
}

\author{
Sharon Elad • Judith E. Raber-Durlacher • Michael T. Brennan • Deborah P. Saunders • \\ Arno P. Mank • Yehuda Zadik • Barry Quinn • Joel B. Epstein • Nicole M. A. Blijlevens • \\ Tuomas Waltimo • Jakob R. Passweg • M. Elvira P. Correa • Göran Dahllöf • \\ Karin U. E. Garming-Legert • Richard M. Logan • Carin M. J. Potting • Michael Y. Shapira • \\ Yoshihiko Soga • Jacqui Stringer • Monique A. Stokman • Samuel Vokurka • \\ Elisabeth Wallhult • Noam Yarom • Siri Beier Jensen
}

Received: 24 May 2014 / Accepted: 30 July 2014 /Published online: 5 September 2014

(C) Springer-Verlag Berlin Heidelberg 2014

\begin{abstract}
Purpose Hematology-oncology patients undergoing chemotherapy and hematopoietic stem cell transplantation (HSCT) recipients are at risk for oral complications which may cause significant morbidity and a potential risk of mortality. This emphasizes the importance of basic oral care prior to, during and following chemotherapy/HSCT. While scientific evidence is available to support some of the clinical practices used to manage the oral complications, expert opinion is needed to shape the current optimal protocols.

Methods This position paper was developed by members of the Oral Care Study Group, Multinational Association of Supportive Care in Cancer/International Society of Oral Oncology
\end{abstract}

\footnotetext{
S. Elad $(\bowtie)$

Division of Oral Medicine, Eastman Institute for Oral Health, University of Rochester Medical Center, 625 Elmwood Ave., Rochester, NY 14620, USA

e-mail: SElad@URMC.Rochester.edu

S. Elad

Wilmot Cancer Center, Strong Memorial Hospital, University of Rochester Medical Center, Rochester, NY, USA

J. E. Raber-Durlacher

Department of Oral and Maxillofacial Surgery, Academic Medical Center Amsterdam, University of Amsterdam, Amsterdam, The Netherlands
}

(MASCC/ISOO) and the European Society for Blood and Marrow Transplantation (EBMT) in attempt to provide guidance to the health care providers managing these patient populations. Results The protocol on basic oral care outlined in this position paper is presented based on the following principles: prevention of infections, pain control, maintaining oral function, the interplay with managing oral complications of cancer treatment and improving quality of life.

Conclusion Using these fundamental elements, we developed a protocol to assist the health care provider and present a practical approach for basic oral care. Research is warranted to provide robust scientific evidence and to enhance this clinical protocol.

\footnotetext{
J. E. Raber-Durlacher

Department of Medical Dental Interaction and Department of Periodontology, Academic Centre for Dentistry Amsterdam (ACTA), University of Amsterdam and VU University, Amsterdam, The Netherlands

M. T. Brennan

Department of Oral Medicine, Carolinas Medical Center, Charlotte, NC, USA

D. P. Saunders

Department of Dental Oncology, North East Cancer Center, Health Sciences North, Sudbury, ON, Canada
} 
Keywords Oral $\cdot$ Dental $\cdot$ Hygiene $\cdot$ Hematology Hematopoietic stem cell transplantation $\cdot$ Cancer

\section{Introduction}

Hematology-oncology patients and patients undergoing hematopoietic stem cell transplantation (HSCT) are a unique

\section{A. P. Mank \\ Department of Hematology and Oncology, Academic Medical \\ Centre, University of Amsterdam, Amsterdam, The Netherlands}

\section{Y. Zadik}

Israeli Air Force General Surgeon Headquarters, Israel Defense

Forces Medical Corps, Tel Hashomer, Jerusalem, Israel

\section{Y. Zadik}

Department of Oral Medicine, Hadassah School of Dental Medicine, Hebrew University, Jerusalem, Israel

B. Quinn

Department of Cancer and Palliative Care, Chelsea and Westminster NHS Foundation Trust, London, UK

B. Quinn

Department of Cancer Nursing, University of Surrey, Guildford, Surrey

\section{J. B. Epstein}

Samuel Oschin Comprehensive Cancer Institute, Cedars-Sinai

Medical Center, Los Angeles, CA, USA

\section{J. B. Epstein}

Division of Otolaryngology and Head and Neck Surgery, City of Hope, Duarte, CA, USA

\section{N. M. A. Blijlevens}

Department of Haematology, Radboud University Medical Center, Nijmegen, The Netherlands

\section{T. Waltimo}

Klinik für Präventivzahnmedizin und Orale Mikrobiologie,

Universitätskliniken für Zahnmedizin der Universität Basel, Basel, Switzerland

\section{J. R. Passweg}

Klinik Hämatologie, Bereich Innere Medizin, Universitätsspital Basel, Basel, Switzerland

\section{E. P. Correa}

Oral Medicine, Dental Ambulatory of the Hematolgy and Hemotherapy Center, Department of Oral Pathology, Piracicaba Dental School, University of Campinas, Campinas, Brazil

\section{G. Dahllöf}

Department of Dental Medicine, Division of Pediatric Dentistry, Karolinska Institutet, Huddinge, Sweden

K. U. E. Garming-Legert

Department of Dental Medicine, Division of Orofacial Diagnostics and Surgery-Oral Medicine and Pathology, Karolinska Institutet, Huddinge, Sweden cancer patient population. The main characteristic of this patient population is that they experience myelosuppression and immunosuppression due to their disease, the cancer therapy or both and immune-mediated outcomes in survivorship. Frequently, all blood lineages are affected resulting in neutropenia, thrombocytopenia and anemia.

This damage to the blood cells and immunosuppression result in a common profile of oral complications that include

\section{R. M. Logan}

Oral Diagnostic Sciences, School of Dentistry, The University of Adelaide, Adelaide, South Australia

C. M. J. Potting

Department of Hematology, Radboud University Medical Center, Nijmegen, The Netherlands

M. Y. Shapira

BMT \& Cancer Immunotherapy Department, Hadassah-Hebrew University Hospital, Jerusalem, Israel

Y. Soga

Division of Hospital Dentistry, Central Clinical Department, Okayama University Hospital, Okayama, Japan

J. Stringer

Haematology Transplant Unit, The Christie NHS Trust, Wilmslow Road, Manchester M20 4BX, UK

\section{A. Stokman}

Departments of Radiotherapy and Oral and Maxillofacial Surgery, University Medical Center Groningen, University of Groningen, Groningen, The Netherlands

S. Vokurka

Department of Haematology-Oncology, University Hospital in Pilsen, Plzen (Pilsen), Czech Republic

\section{E. Wallhult}

Section of Haematology and Coagulation, Department of Internal Medicine, Sahlgrenska University Hospital, Göteborg, Sweden

N. Yarom

Department of Oral and Maxillofacial Surgery, Sheba Medical Center, Tel-Hashomer, Israel

N. Yarom

Department of Oral Pathology and Oral Medicine, School of Dental Medicine, Tel-Aviv University, Tel-Aviv, Israel

S. B. Jensen

Section of Oral Medicine, Clinical Oral Physiology, Oral Pathology and Anatomy, Department of Odontology, Faculty of Health Sciences, University of Copenhagen, Copenhagen, Denmark 
infections, bleeding and anemia-related oral manifestations (75). Furthermore, direct and indirect effects of cytotoxic therapies to oral tissues lead to a series of additional complications. For example, mucositis, dry mouth and dysgeusia are frequently observed in these patients (Table 1). Oral complications differ in their timing and duration with some referred as early complications, while some develop later following cancer treatment presenting survivorship issues.

Oral complications in these patient populations are common and estimated to affect $80 \%$ of patients [1-4]. These oral complications have a significant impact on the patient's oral function, including the basic need to eat, drink or speak. Pain is also often associated with these oral complications and may lead to increased need for systemic narcotics, increased length of stay at hospital and an increased risk for life-threatening systemic infections [5]. All these sequelae may lead to impaired health-related quality of life (QoL) adversely affecting the patient and his or her family. Some patients have rated oral mucositis as the most distressing aspect of anti-cancer treatment [6]. Therefore, it is well-recognized that attempts should be made to prevent oral complications, ease the patient's pain and minimize late consequences.

Several oral care guidelines have been published in an attempt to assist the clinician [7-14]. However, the clinical practice of oral care varies between and within centers and may not always be optimal. There are various reasons for this, including the availability of oral/dental care services in cancer centers, difficulty with implementing guidelines into daily practice, lack of consistency between various guidelines and preference of traditional views over scientific evidence [15].

The aim of this position paper is to clearly state the recommendation of the Multinational Association of Supportive Care in Cancer/International Society of Oral Oncology (MASCC/ISOO) and the European Society for Blood and Marrow Transplantation (EBMT) for basic oral care in patients with hematologic cancer and those undergoing HSCT.

This position paper does not intend to detail the specific management protocols of various oral complications related to the underlying disease or related to the cancer treatment. An overview of such oral complications is included in the

Table 1 Oral complications in hematology-oncology patients and HSCT recipients

\begin{tabular}{|c|c|c|c|c|}
\hline Category & Tissue & Oral complication & $\begin{array}{l}\text { Early } \\
\text { presentation }\end{array}$ & $\begin{array}{l}\text { Late } \\
\text { presentation }\end{array}$ \\
\hline \multirow[t]{19}{*}{ Tissue-specific manifestations } & \multirow[t]{5}{*}{ Mucosa } & Mucositis & + & + \\
\hline & & Atrophy and burning, paleness (anemia) & + & \\
\hline & & Neutropenic ulcer & + & \\
\hline & & Lichenoid, erythema and ulcers (cGVHD) & & + \\
\hline & & Pyogenic granuloma & & + \\
\hline & \multirow[t]{3}{*}{ Salivary glands } & Salivary gland hypofunction & + & + \\
\hline & & Sialadenitis & + & + \\
\hline & & Mucocele (cGVHD) & & + \\
\hline & \multirow[t]{3}{*}{ Musculo-skeletal } & $\begin{array}{l}\text { Loss of elasticity, reduced range of motion and limited mouth } \\
\text { opening (i.e. scleroderma-like manifestations) (cGVHD) }\end{array}$ & & + \\
\hline & & Drug-induced osteonecrosis of the jaw & & + \\
\hline & & Temporomandibular disorders & & + \\
\hline & \multirow[t]{3}{*}{ Sensory disturbances } & Dysgeusia & + & + \\
\hline & & Neuropathy & & + \\
\hline & & Tooth hypersensitivity & & + \\
\hline & \multirow[t]{5}{*}{ Teeth and gingivae } & Increased dental demineralization and caries & & + \\
\hline & & Gingival enlargement & & + \\
\hline & & Desquamative gingivitis (cGVHD) & & + \\
\hline & & Acute periodontal infections (symptomatic) & + & + \\
\hline & & Pre-existent chronic periodontal infections (asymptomatic) & + & + \\
\hline \multirow[t]{5}{*}{ Non-tissue-specific manifestations } & & Bleeding & + & + \\
\hline & & Infection - bacterial, viral, fungal & + & + \\
\hline & & Squamous cell carcinoma & & + \\
\hline & & Post-transplantation lymphoproliferative disorder & & + \\
\hline & & $\begin{array}{l}\text { Developmental disturbances of teeth and craniofacial growth } \\
\text { in pediatric patients }\end{array}$ & & + \\
\hline
\end{tabular}

HSCT hematopoietic stem cell transplantation, $c G V H D$ chronic graft versus host disease 
systematic reviews of the MASCC/ISOO and is of assistance in addressing: bisphosphonate osteonecrosis [16], dysgeusia [17], oral fungal infection [18], oral viral infection [19], dental disease [20], osteoradionecrosis (ORN) [21], trismus [22], oral pain [23], xerostomia and salivary gland hypofunction $[24,25]$ and mucositis [26-34].

\section{Basic oral care}

Basic oral care (BOC) is defined as the activities that should be part of the patient's routine care during periods of cancer treatment in order to maintain good oral health and reduce the risk for local inflammation and infection, as well as systemic infection originating from the oral cavity.

The objectives of BOC are the following: (1) prevention of infection: to prevent infections of the oral mucosa and the periodontium and to prevent regional spread and systemic infection; (2) pain control: reduce discomfort and pain in the mouth; (3) maintain oral functions: promoting oral nutritional intake, oral fluid intake and capability to speak; (4) managing the complications of the cancer treatment: reduce the adverse effect of radiation therapy, chemotherapy and newer targeted therapies (Table 1); and (5) improve QoL of the patient (Fig. 1).

The recommendations will be presented per objective. However, some practice recommendations address several objectives.

These objectives have relevance before, during and after cancer therapy. Prevention and management of long-term complications and maintenance of oral and dental health are relevant for patients lifelong following the completion of cancer therapy.

\section{Recommendations}

\section{Before chemotherapy/HSCT}

\section{Prevention of infections}

A comprehensive dental and oral evaluation is the recommended standard of care prior to high-dose chemotherapy/ HSCT in order to eliminate sources of infection, both odontogenic and non-odontogenic. The dental treatment plan should be definitive. It has been shown that dental treatment prior to chemotherapy/HSCT may prevent the additional death of 18 out of every 10,000 patients and may reduce systemic infections by approximately one-third ( 250 versus 318 out of every 1,000 patients) [35]. Ideally, an initial appointment should be scheduled as early as possible in order to allow sufficient time to deliver emergent and urgent dental needs including dental extractions as well as professional periodontal care (e.g. dental cleaning and oral hygiene instruction) and to allow time for tissues to heal post-operatively/ post-dental extractions, preferably with a healing period of
2 weeks. Principles of treatment planning in patients prior to chemotherapy were suggested by an experts' forum and can be found online $[1,13]$. Nevertheless, time constraints as well as the medical condition itself may require modification of the dental treatment plan $[36,37]$. Dental treatment planning requires that the dentist understands principles of oncology care, the diagnosis and treatment plan for the patient. It also requires close consultation with the medical team especially regarding unresolved oral health issues that may interrupt or complicate cancer treatment. Integrated health care teams promote integrated health care planning. Patients need to be informed about the dental treatment plan. There may be elective additional dental needs at the time of the examination that can be addressed after the chemotherapy or HSCT, when the patient's overall health status allows, and it has been approved by the medical management. Close coordination and communication between the different disciplines involved is therefore necessary and is facilitated by integrated health care teams.

\section{Pain control}

Prior to chemotherapy or HSCT, the dental health care provider should take steps to ensure no traumatic and anatomic factors may induce pain during and after cancer treatment. Therefore, as part of the dental evaluation, the dentist should eliminate potential sources of intra-oral trauma such as illfitting dentures, orthodontic appliances, deficient/rough restorations, traumatic dentition and dental calculus.

Furthermore, cancer therapy itself commonly results in pain $[38,39,23]$. A consultation with an oral medicine specialist or a dentist experienced in managing oral complications is recommended if atypical pain develops during the delivery of oncology care.

\section{Maintaining oral function}

Based on the need to eliminate sources of infection prior to chemotherapy, non-restorable teeth, including exposed root tips, severely periodontally involved teeth, and impacted teeth with signs of pericoronitis, should be extracted. Due to time constraints, a determinative approach should be adopted for restorable teeth (i.e. tooth extraction if there is insufficient time to confirm that a focus of pulpal/periapical infection is resolved, and sites of periodontal infection require definitive management). Often, in neglected dentitions, this principle dictates multiple extractions. The elimination of sharp or fractured teeth, restorations and prostheses will prevent trauma to the oral mucosa and thus will reduce risk for oral bleeding and infection. The dentist should consider a dental plan that will restore the occlusal surface to the level that will allow the patient to eat comfortably. The medical team should be aware of the patient's oral status and adjust foods to the chewing capabilities of the patient. A nutritionist's consultation may be needed. 


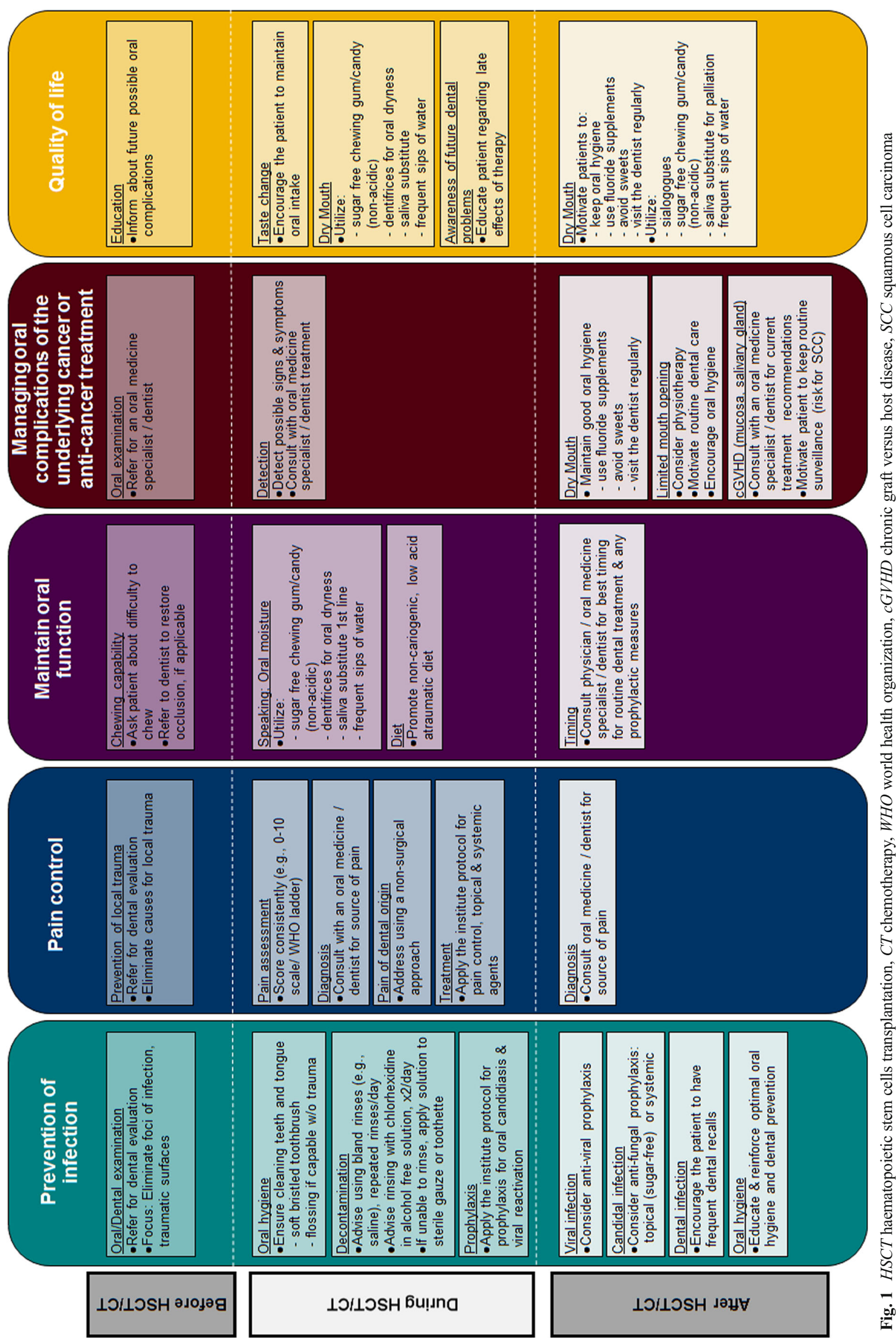




\section{Managing oral complications of treatment}

Considering that this section is aimed at patients pre-chemotherapy/HSCT, it is unlikely that they would have oral complications related to their cancer treatment. The underlying disease however may present with oral manifestations. The medical and dental team should recognize the potential for oral involvement of the underlying disorder and refer the patient for a complete oral evaluation if an oral symptom is reported or oral lesion is observed.

\section{$Q o L$}

It is important to provide support and help the patient to understand what is expected during chemotherapy or HSCT; oral survivorship issues can be introduced, for example, the expected and usually reversible mucositis and hyposalivation. Possible long-term consequences and prevention strategies should be communicated. Assistance of clinical coordinators or social workers may be needed for coordinating the delivery of the treatment.

\section{During chemotherapy/HSCT}

\section{Prevention of infections}

Maintenance of good and intensified oral hygiene is a fundamental component of BOC. Gingival and mucosal inflammation caused by oral bacteria and mucosal barrier injury increases the risk of bacteremia. Intensive oral hygiene can reduce the incidence and severity of mucositis [40, 41]. Additionally, it has been reported that oral and periodontal assessment and management reduce the risk of infection and fever associated with oral conditions [42-45]. Lastly, minimizing gingivitis and periodontitis will result in less gingival bleeding. Therefore, patients benefit from maintaining good oral hygiene thereby keeping the oral microbial load low.

Oral hygiene refers to the actions taken to remove dental plaque from the teeth, to reduce the amount of oral bacteria in the oral cavity and to wash away solid debris. Plaque left on the gingival margin may cause gingivitis, which can lead to bleeding of the gums and infection in immunocompromised patients. Compliance may be compromised due to oral pain, nausea and other complications during cancer treatment; however, it is important to encourage the patient to adhere to the treatment protocol. The additional use of topical anesthetics/ analgesics can help make this task easier in times when oral mucositis is present such as viscous xylocaine, dyclonine or diphenhydramine for those with allergies to esters and amides; topical analgesics such as doxepin and opioids may also reduce pain thus facilitating oral care [23]. When oral hygiene is compromised, the addition of chlorhexidine (CHX) as an oral antiseptic could be considered due to its reducing impact on the oral microflora. The MASCC/ISOO clinical practice guidelines found no evidence to support $\mathrm{CHX}$ rinse in the management of oral mucositis; however, this does not imply that it should not be used for other purposes, such as prevention of infection. Topical applications may cause local adverse events (for example, CHX may induce reversible staining of dental and oral tissues), and the patient should be so informed.

A combination of different oral hygiene products will achieve best removal of plaque from all surfaces of the teeth. Brushing should be continued two to three times a day. An ultra-soft or a soft toothbrush with bristles softened in hot water is preferred. Air-drying the toothbrush between uses is recommended. The toothbrush should be replaced regularly; in addition, some authors recommend the replacement of toothbrush after each neutropenic cycle [46]. Toothpaste with fluoride is recommended [47]. High concentration fluoride toothpastes (e.g. $1.1 \%$ sodium fluoride) are available by prescription and should be provided if increased risk of dental caries is anticipated. A non-mint-flavored toothpaste may be suitable during days of mucosal injury. Likewise, toothpastes containing sodium dodecyl sulfate (surfactant) should be avoided if it irritates the mucosa. Brushing with sponge brushes is optional but less effective to remove dental plaque and preventing gingivitis [48], although with the addition of a CHX solution, effectiveness increases [48]. Additional measures to remove dental plaque from between teeth, crowns/ bridges or dental implants and from the tongue should be continued using devices that the patient is familiar with in order to avoid self-injury due to lack of experience [49].

Frequent rinsing with bland solutions is recommended although it should be emphasized that oral rinses are not a substitute for mechanical cleaning. The neutral formulas are basically salty water and/or baking soda rinse $(0.9 \%$ saline and/or $0.5 \%$ sodium bicarbonate solution, respectively) [7, 13]. Oral rinses with active agents can be combined as long as there is no antagonism between the active agents (for example, calcium phosphate rinse, CHX rinse) [7, 13]. The efficacy of these agents for mucositis prevention is debated in the literature. However, the anti-microbial effect of CHX is not questioned, and the washing effect of these liquids is valid. Notwithstanding that, CHX use is limited to twice daily for the duration of the neutropenia [50-52]. The non-alcoholic and non-flavored CHX digluconate $0.12-0.2 \%$ solution may be easier to tolerate for patients with sensitive oral mucosa. Scientific evidence about the effectiveness of CHX in various concentrations, duration of rinse and cross-reaction is available in the literature [53,54]. Oral adverse effects are usually reversible (teeth and tongue discolouration and taste changes) [55]. Possible substitute for topical disinfectants are octenidine and polyhexanide.

Removable dental prosthesis should be cleaned in a similar manner with mechanical aids and multiple washes, and when not in use (during nights, or as often as the patient can 
accommodate), the dentures should be placed preferably in a cleaning solution or in water. A range of cleaning solutions for dentures is available (e.g. CHX, enzymes, sodium hypochlorite, oral rinses or peroxide solutions). However, there is limited evidence to suggest the use of a specific cleaning solution or recommend that one solution should be preferred over another in terms of health of the denture-bearing mucosa [56]. Despite this, however, the use of a watery solution to clean the dentures and in which to store the dentures when not in use will assist in maintaining the integrity of the acrylic.

Other components of the BOC refer to prophylaxis against oral candidiasis and viral reactivation $[19,18]$. The protocols for this can vary considerably between medical centers. This variability may reflect the doctrine of the medical team in a certain location but also the geographical variability in the oral microflora and resistant strains [57]. It is advised that the oral cavity be examined on a daily basis for early changes including possible signs of oral infection. An oral medicine specialist or experienced dentist may assist whenever oral pathology is suspected.

\section{Pain control}

Pain control is an important element, particularly since during this period, oral mucositis may develop [58-60]. This topic has been extensively reviewed $[23,7,61,62,13]$. Generally, it is important to conduct a pain score on a regular basis. There are several pain ladders that can be used to score the pain level $[63,10]$.

Treatment will be adjusted individually according to the patient response to first lines of treatment. These include topical analgesics/anesthetics and mucosal coating agents (listed in Guide for Oral Care in Cancer Therapy [7]) and non-opioids and opioids analgesics (pain management is reviewed elsewhere) $[62,31]$. The advantage of topical agents is the paucity of adverse effects. However, most of the evidence-based data refer to systemic medications, including patient-controlled analgesia [12, 64]. The importance of neuropathic pain in cancer patients due to chemotherapy and in tissue damage due to mucositis has been of increasing interest and is an important reason for pain continuing despite the use of topical agents and nociceptive analgesics [23, 62]. Nonpharmacologic modalities (such as low-level laser therapy, relaxation/imaginary techniques, hypnosis) to relieve pain are well reported in the literature and can be used as an adjunctive modality [62].

\section{Maintaining oral function}

Pain control alone is insufficient to allow oral function during the time period at risk for oral mucositis. Another early effect of chemotherapy is dry mouth. Without the lubricating effect of saliva, the oral mucosa is in continuous friction with other mucosal surfaces, teeth and with oral intake. The ability to eat, swallow and speak can be impaired when the mouth is dry. Therefore, interventions to keep the mouth moist are important. This includes palliation by sipping or spraying water or various saliva substitutes and mechanical-taste stimulants (chewing gum, sweet-sour candies) and the use of frequent bland rinses [7, 24, 13]. Some clinicians suggest using the spray or mouth-rinse during daytime and gel during night since the moisturizing effect of the more viscous consistency of the gel tends to last longer. It is important that any saliva stimulants are sugar-free and low in acid in order to avoid increased risk for dental decay, tooth sensitivity and erosion. Likewise, keeping the lips lubricated will prevent lips from getting dry and fissured. Some clinicians prefer lanolin- or cocoa butter-based lipsticks/creams over petroleum-based products.

The patient's diet should be adjusted to the mucosal sensitivity level. This may include avoiding crispy/rough foods and acidic, spicy and hot foods in order to increase the likelihood that the diet will be tolerable, particularly if oral mucositis is evident. If topical anaesthetics are used to control mucosal sensitivity, patients should be instructed to chew and swallow carefully in order to avoid trauma or aspiration. A nutrition specialist and the responsible physician should be consulted if food intake is limited.

\section{Managing oral complications of chemotherapy/HSCT}

The list of acute oral complications (Table 1) is long and represents the complexity of these patients. This topic is beyond the scope of this paper. Generally, each of these diagnoses should be addressed separately according to the current best evidence.

\section{$Q o L$}

QoL questionnaires, such as EORTC OH-17 and OHIP-14, may facilitate the monitoring of the oral complications. The combination of pain control, prevention of local infection and maintaining saliva secretion contribute considerably to oral health-related QoL. However, some of the oral complaints may resolve with time in some patients such as taste change or saliva dysfunction. For example, most patients will regain taste function as early as a few weeks after the end of chemotherapy/HSCT, while in others, taste dysfunction may persist for as long as 2 years post-HSCT [65]. Despite difficulties, it is important to encourage the patient to maintain oral intake while suffering from dysgeusia [66, 17].

Dry mouth also impacts QoL. As described above, complaints can be relieved with systemic sialogogues and to some extent by stimulation by topical means. Studies have shown that patients consider the complications of oral mucositis and dry mouth as very debilitating when asked for their perception of the entire period of hospitalization following HSCT [67]. Therefore, the health care provider should address these complaints seriously and support the patient. 


\section{After chemotherapy/HSCT}

\section{Prevention of infections}

Infections developing after chemotherapy/HSCT are common in two instances. Firstly, when white cell counts are low, the patient is at risk for infections; the most common are candidal and herpetic infections $[18,19]$. These immunosuppressed patients are likely to be prescribed with antibiotics, which in turn will change the oral microflora and will contribute to emergence of oral candidiasis. Therefore, if the patient is neutropenic or the dose of an immunosuppressive agent is increased, a prophylactic dose of an anti-fungal and anti-viral may be considered, if not already in place. Secondly, when a dry mouth is long-standing, the patient is at risk of oral candidiasis and dental damage. Therefore, if repeated candidal infections occur, the clinician should consider instituting a prophylactic anti-fungal treatment. In patients treated with topical corticosteroids for oral chronic graft versus host disease (cGVHD) (see below), the risk for oral candidiasis further increases. For effective prevention of oral candidiasis, in patients having dentures, the denture should be decontaminated with the same anti-microbial agent to prevent recontamination of the oral cavity by the denture's microbial flora.

Dental disease should be considered as a source of infection and therefore should be managed routinely. Risk factors for dental decay, such as hyposalivation, should be addressed. Dental providers must be informed and may need to be directed with respect to avoiding invasive treatment. Procedures that generate aerosols (e.g. removal of dental plaque deposits using an ultrasonic scaler), which may lead to aspiration, should be minimized if the patient is immunosuppressed. It is critical that dental treatment be provided in the context of the systemic status of the patient. Integrated medical and dental teams function best in this regard. The nursing team should encourage patients to visit an experienced dental professional to address dental needs whenever blood counts stabilize and to consult with the oncology team to assist in dental care, specifically surgical intervention. Immune reconstitution may take months after the HSCT, even when hematological status is apparently normal and any dental intervention should be provided in the context of systemic health, and again with experienced health care teams [68].

\section{Pain control}

Pain aetiology in the long-term post-transplant phase differs from acute pain in the immediate time period post-chemotherapy/HSCT. Chronic mucosal diseases such as GVHD become the main reason for pain. Symptomatic gingival involvement of cGVHD (desquamative gingivitis) may further limit the patient's ability to brush the teeth. In addition, local infection, dental disease and neuropathic causes of oral pain are common causes of oral pain in patients following chemotherapy or in HSCT survivors. Topical palliative treatment for oral cGVHD may be helpful $[8,69]$. In addition to therapy directed to the pain, it is important to direct the therapy to the underlying disease, such as GVHD [8, 69]. Additional topical and systemic and complementary pain management techniques are available (reviewed in Epstein et al.) [62]. Expectations for full control of pain are often limited by systemic adverse effects.

\section{Maintaining oral function}

Following the stabilization of blood counts and immune status, patients should be advised to have dental needs addressed, particularly the dental needs that were identified at the initial appointment and were not considered a priority to complete prior to the chemotherapy/HSCT. Treatment planning, particularly any potential surgical care, must be planned with the medical team prior to intervention. Dental preventive strategies can be reinforced. Dental rehabilitation (e.g. crowns, bridges, dentures) will enable the patient to perform basic oral functions. Medical centers may vary in the duration of the time-window in which dental treatment is avoided.

The role of saliva in maintaining oral function is a constant factor to consider. Methods to relieve salivary hypofunction and/or xerostomia (the objective and subjective components of dry mouth, respectively) may be best managed by use of sialogogues when residual function is documented; palliation is outlined above. Management modalities, such as acupuncture and intra-oral electro-stimulator, may be considered $[24,70]$.

\section{Managing oral complications of chemotherapy/HSCT}

In addition to chronic oral complications (i.e. cGVHD, dry mouth), it is important to inform the patients with salivary dysfunction that they are at increased risk for dental decay [71]. Management of hyposalivation should be addressed. The patient should be motivated to maintain oral hygiene, use fluoride supplements (may be applied directly onto the dentition or in individual trays, in-office as well as in-home methods), avoid sweets and visit the dentist regularly. Artificial sweeteners can be used as a substitute for sugar-based sweets. In this regard, xylitol is preferred as it is not a digestible carbohydrate for Streptococcus mutans, the main caries pathogen, and is a neurostimulant of salivary secretion at higher doses $\left(6-12 \mathrm{~g} \mathrm{day}^{-1}\right)$ [72]. In patients with elevated risk to high plaque levels, the addition of $\mathrm{CHX}$ and remineralizing agents such as calcium- and phosphate-based products should be considered [73].

Chronic GVHD may manifest as scleroderma-like disease with progressive damage decreasing the elasticity of oral tissues. Limited mouth opening can disturb the patient's basic oral functions and may even put the patient at risk for aspiration. The ease of performing and receiving dental care can be 
increasingly difficult because of this limited mouth opening; unfortunately, little can be done to treat established scleroderma $[74,75]$ although physiotherapy with an active exerciser has been suggested to delay its progression. Additional pharmacologic and surgical treatment modalities have been reported [75]. When scleroderma-type cGVHD has developed, extra care should be delivered to maintain oral hygiene and treat all the dental needs before mouth opening will limit the capability to deliver dental treatment.

Patients with cGVHD are at a greater risk for oral squamous cell carcinoma (SCC) [76]. Therefore, these patients should be under routine surveillance by their oral health care provider at least once a year or more frequently depending on the level of oral cGVHD involvement.

Patients post-HSCT are often treated with high-dose steroids, which in turn result in osteoporosis. The treatment for osteoporosis is mostly with bisphosphonates, which are associated with osteonecrosis of the jaws (ONJ). Additional antiresorptive and anti-angiogenesis drugs (denosumab, bevacizumab and sunitinib) were reported to be associated with ONJ [77]. The guidelines of the American Academy of Oral and Maxillofacial Surgery address the prevention, treatment and dental management of patients on these medications [78].

Children are also at risk of developing disturbances in dental development and craniofacial growth (see 'Pediatric patient population' section) particularly those subjected to total body irradiation (TBI) at an early age. Eruption of teeth should be monitored. Growth and development may also be altered if puberty is affected by cancer therapy.

\section{QoL}

Dry mouth negatively impacts QoL [79]. It has been reported that protocols including TBI have a greater tendency to cause irreversible damage to the salivary glands [80]. However, less toxic conditioning regimens may also have a long-term effect on salivary function [81]. Following chemotherapy/HSCT, dry mouth may be a result of the cytotoxic treatment itself and also due to the use of multiple drugs that may affect salivary secretion. Involvement of the salivary glands with cGVHD can also reduce salivary secretion. Treatment trials with systemic sialagogues may be offered to the patient [8]. Efficacy of sialagogues varies between patients, and adverse effects and interaction with other medications have to be considered. Persistent taste dysfunction is anticipated to affect diet, oral intake and QOL, as well as impacting caloric and nutrient intake with systemic implications [66].

Pediatric patient population

This has been covered in the guidelines on dental management of pediatric patients receiving chemotherapy, HSCT and/or radiation published by the American Academy of Pediatric
Dentistry. In this position paper, we would like to point to several specific aspects $[82,9,83]$.

\section{Pain control}

Children may have difficulty communicating and describing their pain. Selection of a suitable pain scale depends on the comprehension level of the patient. Topical oral administration of local anaesthetics such as lidocaine and benzocaine in children should be avoided because of the risk for serious adverse effects including deaths [84].

\section{Prevention of infections}

Ideally, children should be referred for an initial consult to a pediatric dentist integrated with the cancer team [83].

Many children preparing for chemotherapy/HSCT have pre-existing oral diseases, and those with high caries prevalence are at risk to develop new lesions. Advanced decay may develop into a source of infection. Fluoride preparations include toothpastes, and fluoride supplements (gels, rinses or varnishes) prevent dental caries. If a higher fluoride concentration is required and the oral mucosa is sensitive, it is recommended to use a neutral $\mathrm{pH}$ fluoride gel.

\section{Maintaining oral function}

Optimal oral care is needed in order to minimize oral problems and discomfort before, during and after treatment as well as the possible acute and long-term effects of therapy on the developing craniofacial complex. Patient and parents' education plays a major role to achieve collaboration for long-term surveillance. It is important to emphasize the need for regular follow-up visits at a dental office and in complex cases with an experienced oral medicine professional.

\section{Managing oral complications of chemotherapy/HSCT}

Generally, the same concepts of management used in adults are applicable for children with the exception of drugs that are registered specifically for use in adults. Additionally, it should be noted that some of the clinical practice guidelines defined by leading international organizations are generalizing adult and pediatric patient population. Thus, effectiveness of a specific intervention may not be guaranteed in pediatric patients.

One particular aspect of salivary dysfunction in children is that they rarely complain about mouth dryness, even though they objectively have a very low salivary output. An interview that focuses on everyday situations may reveal signs and symptoms of mouth dryness [85].

In respect to potential dental source for oral complication, it was suggested that extraction of loose primary teeth will reduce the risk for bleeding during periods of thrombocytopenia. This 
aspect should be discussed with the patient and the parents during the dental clearance prior to the chemotherapy/HSCT.

\section{Discussion}

This position paper represents expert opinion of experienced clinicians in the field of oral oncology, hematology and nursing. The systematic reviews about oral complications for cancer patients tend to state guidelines that are evidence-based only. As a result, there are gray zones where practitioners are left without guidelines and without consensus of how to care for patients. This position paper provides a base for consensus and provides recommendations with the goal of presenting current best clinical practices.

An important aspect of promoting improved oral care of patients undergoing chemotherapy/HSCT is by developing an integrated treatment team including medical, dental, nursing, nutrition, physical therapy and counseling providers. Training and continuing education programs will ensure that the knowledge will diffuse to an extensive community of health care providers, which in turn could make a positive impact on patients' health care.

This position paper is directed at the entire multidisciplinary health care team (Fig. 2). Terminology to describe the
Fig. 2 Suggested collaboration of hematology/oncology and oral medicine/dental teams as part of basic oral care for oncologic patients

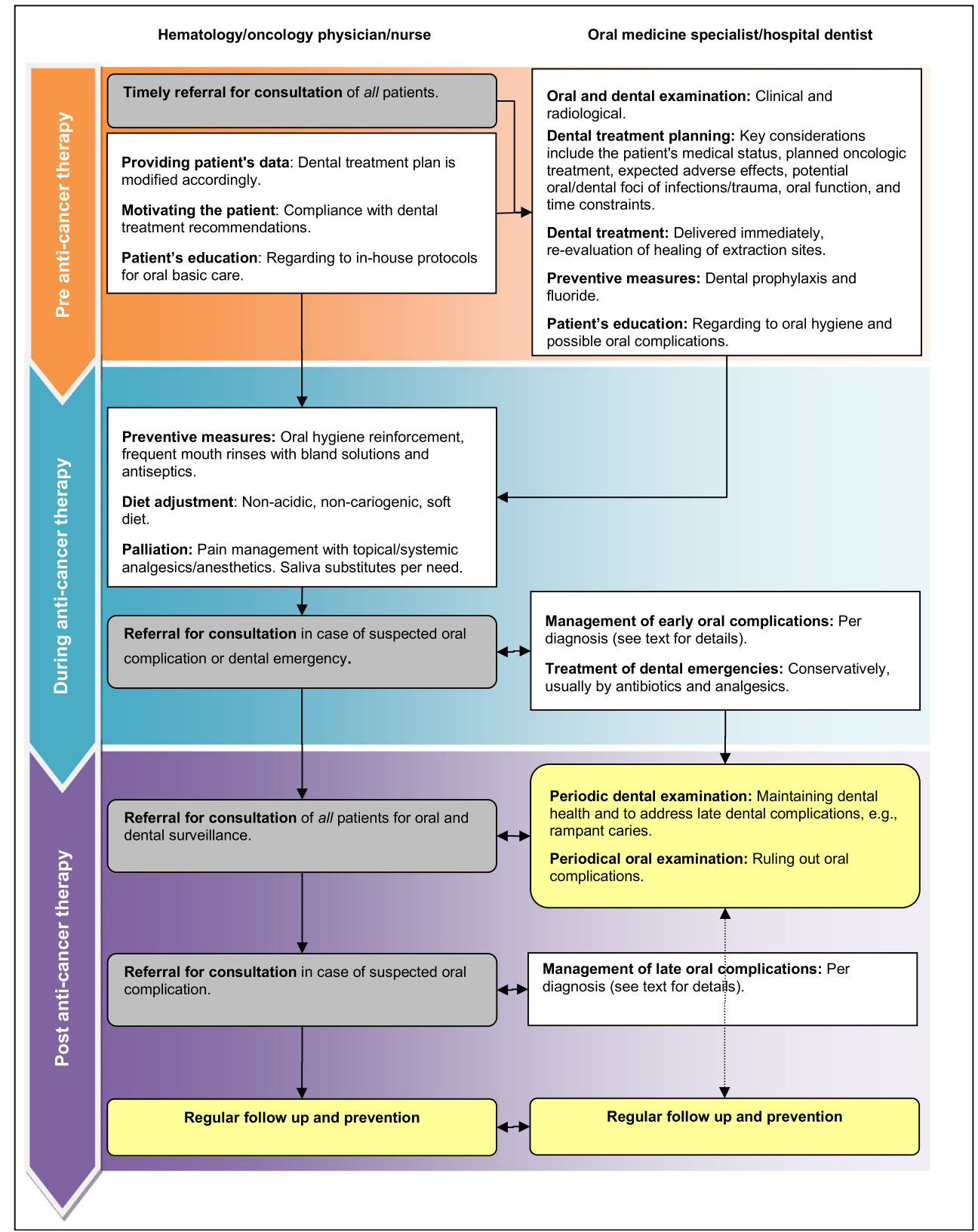


dental professional varies across the globe. A global term ('dentist') was therefore used in this manuscript to refer to a dental-oral care provider who is educated and experienced in delivering oral health care for oncology patients. Such knowledge should include understanding of the implications of the medical background on the dental treatment plan and managing oral complications. The primary dentist in the community may have an important role in the preparation of the patient ahead of their chemotherapy/HSCT and in routine dental care following the treatment but will need guidance of the oncology team or the hospital dental team. The axis between the primary dentist, the dentist/oral medicine specialist at the cancer center and the medical team is essential for adequate and timely clearance of dental and oral infections. To this end, the dentist in the community should have continuing education about the dental treatment planning in oncology in general and for hematology-oncology patients and those following HSCT. More information for dental practitioners about the recommended treatment can be found in the literature [ $[7,20$, $13,83,86]$.

As the profile of HSCT changes from myeloablative protocols to non-myeloablative protocols, the spectrum of oral complications and management recommendations may also change. Shorter nadir and lower incidence of severe oral mucositis may lead to new insights with respect to the optimal timing to resume routine dental treatment. On the other hand, there may be more long-term cancer survivors, and patients may be older and have more severe pre-existing dental pathology and complications including an increase of the incidence of GVHD.

In summary, oral and dental care must be recognized as a critical component of care prior to and during chemotherapy/ HSCT and in survivorship. A multi-disciplinary team approach is the key for success in the management of oral complications in hematology-oncology patients including those undergoing HSCT.

\begin{abstract}
Acknowledgments ISOO is grateful to T\&K Corporation for their willingness to support educational projects conducted by ISOO and to enhance the knowledge of medical professionals across the globe. The contributors would like to thank the Oral Care Study Group of MASCC/ ISOO for providing the supporting environment that lead to the maturation of this position paper. The contributors gratefully acknowledge specific input by Dr. D.A. van Strydonck regarding CHX use.
\end{abstract}

Disclosure This study was partly conducted by an unrestricted fund donated by the T\&K Corporation, Tokyo, Japan.

Disclaimer This Position Paper is based on a narrative review of the existing data and the clinical observations of an expert task force composed of professionals experienced in the diagnosis and management of oral complications in hematology patients. It is meant to state the recommendation of MASCC/ISOO and EBMT for basic oral care in hematology-oncology patients and hematopoietic stem cell transplantation recipients. It is not replacing the MASCC/ISOO oral mucositis clinical practice guidelines.
The Position Paper is informational in nature. The authors caution that the strategies described in the Position Paper might not be suitable for every, or any, purpose or application. This Position Paper cannot substitute for the individual judgment brought to each clinical situation by the patient's health care providers. As with all clinical materials, the Position Paper should be used with the clear understanding that continued research and practice could result in new knowledge or recommendations.

Neither MASCC/ISOO nor EBMT grant implies warranty regarding the accuracy, content, completeness, reliability, operability or legality of information contained within the Position Paper. In no event shall the MASCC/ISOO or EBMT be liable to the user of the Position Paper or anyone else for any decision made or action taken in reliance on such information.

\section{References}

1. Bradley LL, Chambers M, Conklin CE, Fox PC, Garden AS, Haveman CW, Jackson SR, Lowenstein NL, Peterson DE, Schubert MM, Sonis ST (2003) Oral health in cancer therapy. A guide for health care professionals. In: Rankin KV, Jones DL, Redding SW (eds) Oral health in cancer therapy. Dallas, Texas

2. Epstein JB, Thariat J, Bensadoun RJ, Barasch A, Murphy BA, Kolnick L, Popplewell L, Maghami E (2012) Oral complications of cancer and cancer therapy: from cancer treatment to survivorship. CA Cancer J Clin 62(6):400-422. doi:10.3322/caac.21157

3. Epstein JB, Raber-Durlacher JE, Wilkins A, Chavarria MG, Myint H (2009) Advances in hematologic stem cell transplant: an update for oral health care providers. Oral Surg Oral Med Oral Pathol Oral Radiol Endod 107(3):301-312. doi:10.1016/j.tripleo.2008.12.006

4. Oral Complications of Chemotherapy and Head/Neck Radiation (PDQ ${ }^{\circledR}$ ) http://www.cancer.gov/cancertopics/pdq/supportivecare/ oralcomplications/HealthProfessional/page1, National Cancer Institute. Accessed on Aug. 2014

5. Elting LS, Cooksley C, Chambers M, Cantor SB, Manzullo E, Rubenstein EB (2003) The burdens of cancer therapy Clinical and economic outcomes of chemotherapy-induced mucositis. Cancer 98(7):1531-1539. doi:10.1002/cncr.11671

6. Bellm LA, Epstein JB, Rose-Ped A, Martin P, Fuchs HJ (2000) Patient reports of complications of bone marrow transplantation. Support Care Cancer 8(1):33-39

7. Epstein J, Haveman C, Huber M, Peterson D, Plemons J, Sanfilippo N, Schubert M, Sonis S (2008) Oral health in cancer therapy. A guide for the health care professionals. In: Rankin K, Jones D, Redding S (eds) Oral health in cancer therapy. San Antonio, Texas

8. Meier JK, Wolff D, Pavletic S, Greinix H, Gosau M, Bertz H, Lee SJ, Lawitschka A, Elad S (2011) Oral chronic graft-versus-host disease: report from the International Consensus Conference on clinical practice in cGVHD. Clin Oral Investig 15(2):127-139. doi:10.1007/ s00784-010-0450-6

9. Guideline on dental management of pediatric patients receiving chemotherapy, hematopoietic cell transplantation, and/or radiation (2008). Pediatr Dent 30 (7 Suppl):219-225

10. Quinn B, Potting CM, Stone R, Blijlevens NM, Fliedner M, Margulies A, Sharp L (2008) Guidelines for the assessment of oral mucositis in adult chemotherapy, radiotherapy and haematopoietic stem cell transplant patients. Eur J Cancer 44(1):61-72. doi:10.1016/ j.ejca.2007.09.014

11. Bystricka E, Ghelase R, Gorican IK, Mazur E, Vokurka S (2012) Oral cavity care in patients after high-dose chemotherapy and stem cell transplantation: the East Forum EBMT Nurses Group standard of care. Bone Marrow Transplant 47(1):149-150. doi:10.1038/bmt. 2011.19 
12. McGuire DB, Correa ME, Johnson J, Wienandts P (2006) The role of basic oral care and good clinical practice principles in the management of oral mucositis. Support Care Cancer 14(6):541-547. doi:10. 1007/s00520-006-0051-8

13. Rankin KV, Epstein J, Huber MA, Peterson DE, Plemons JM, Redding SS, Sanfillippo NJ, Schubert MM, Sonis ST (2009) Oral health in cancer therapy. Tex Dent J 126(5):389-397, 406-319, 422-337

14. UK Oral Mucositis in Cancer. www.ukomic.co.uk. Accessed on Jul. 2014

15. Epstein JB, Parker IR, Epstein MS, Gupta A, Kutis S, Witkowski DM (2007) A survey of National Cancer Institute-designated comprehensive cancer centers' oral health supportive care practices and resources in the USA. Support Care Cancer 15(4):357-362. doi:10. 1007/s00520-006-0160-4

16. Migliorati CA, Woo SB, Hewson I, Barasch A, Elting LS, Spijkervet FK, Brennan MT (2010) A systematic review of bisphosphonate osteonecrosis (BON) in cancer. Support Care Cancer 18(8):10991106. doi:10.1007/s00520-010-0882-1

17. Hovan AJ, Williams PM, Stevenson-Moore P, Wahlin YB, Ohrn KE, Elting LS, Spijkervet FK, Brennan MT (2010) A systematic review of dysgeusia induced by cancer therapies. Support Care Cancer 18(8):1081-1087. doi:10.1007/s00520-010-0902-1

18. Lalla RV, Latortue MC, Hong $\mathrm{CH}$, Ariyawardana A, D'AmatoPalumbo S, Fischer DJ, Martof A, Nicolatou-Galitis O, Patton LL, Elting LS, Spijkervet FK, Brennan MT (2010) A systematic review of oral fungal infections in patients receiving cancer therapy. Support Care Cancer 18(8):985-992. doi:10.1007/s00520-010-0892-z

19. Elad S, Zadik Y, Hewson I, Hovan A, Correa ME, Logan R, Elting LS, Spijkervet FK, Brennan MT (2010) A systematic review of viral infections associated with oral involvement in cancer patients: a spotlight on Herpesviridea. Support Care Cancer 18(8):993-1006. doi:10.1007/s00520-010-0900-3

20. Hong CH, Napenas JJ, Hodgson BD, Stokman MA, MathersStauffer V, Elting LS, Spijkervet FK, Brennan MT (2010) A systematic review of dental disease in patients undergoing cancer therapy. Support Care Cancer 18(8):1007-1021. doi:10.1007/s00520-0100873-2

21. Peterson DE, Doerr W, Hovan A, Pinto A, Saunders D, Elting LS, Spijkervet FK, Brennan MT (2010) Osteoradionecrosis in cancer patients: the evidence base for treatment-dependent frequency, current management strategies, and future studies. Support Care Cancer 18(8):1089-1098. doi:10.1007/s00520-010-0898-6

22. Bensadoun RJ, Riesenbeck D, Lockhart PB, Elting LS, Spijkervet FK, Brennan MT (2010) A systematic review of trismus induced by cancer therapies in head and neck cancer patients. Support Care Cancer 18(8):1033-1038. doi:10.1007/s00520-010-0847-4

23. Epstein JB, Hong C, Logan RM, Barasch A, Gordon SM, OberleEdwards L, McGuire D, Napenas JJ, Elting LS, Spijkervet FK, Brennan MT (2010) A systematic review of orofacial pain in patients receiving cancer therapy. Support Care Cancer 18(8):1023-1031. doi:10.1007/s00520-010-0897-7

24. Jensen SB, Pedersen AM, Vissink A, Andersen E, Brown CG, Davies AN, Dutilh J, Fulton JS, Jankovic L, Lopes NN, Mello AL, Muniz LV, Murdoch-Kinch CA, Nair RG, Napenas JJ, NogueiraRodrigues A, Saunders D, Stirling B, von Bultzingslowen I, Weikel DS, Elting LS, Spijkervet FK, Brennan MT (2010) A systematic review of salivary gland hypofunction and xerostomia induced by cancer therapies: management strategies and economic impact. Support Care Cancer 18(8):1061-1079. doi:10.1007/s00520-0100837-6

25. Jensen SB, Pedersen AM, Vissink A, Andersen E, Brown CG, Davies AN, Dutilh J, Fulton JS, Jankovic L, Lopes NN, Mello AL, Muniz LV, Murdoch-Kinch CA, Nair RG, Napenas JJ, NogueiraRodrigues A, Saunders D, Stirling B, von Bultzingslowen I, Weikel DS, Elting LS, Spijkervet FK, Brennan MT (2010) A systematic review of salivary gland hypofunction and xerostomia induced by cancer therapies: prevalence, severity and impact on quality of life. Support Care Cancer 18(8):1039-1060. doi:10.1007/s00520-010$0827-8$

26. Nicolatou-Galitis O, Sarri T, Bowen J, Di Palma M, Kouloulias VE, Niscola P, Riesenbeck D, Stokman M, Tissing W, Yeoh E, Elad S, Lalla RV (2013) Systematic review of amifostine for the management of oral mucositis in cancer patients. Support Care Cancer 21(1):357364. doi:10.1007/s00520-012-1613-6

27. Migliorati C, Hewson I, Lalla RV, Antunes HS, Estilo CL, Hodgson B, Lopes NN, Schubert MM, Bowen J, Elad S (2013) Systematic review of laser and other light therapy for the management of oral mucositis in cancer patients. Support Care Cancer 21(1):333-341. doi:10.1007/s00520-012-1605-6

28. Peterson DE, Ohrn K, Bowen J, Fliedner M, Lees J, Loprinzi C, Mori T, Osaguona A, Weikel DS, Elad S, Lalla RV (2013) Systematic review of oral cryotherapy for management of oral mucositis caused by cancer therapy. Support Care Cancer 21(1):327-332. doi:10.1007/ s00520-012-1562-0

29. Raber-Durlacher JE, von Bultzingslowen I, Logan RM, Bowen J, AlAzri AR, Everaus H, Gerber E, Gomez JG, Pettersson BG, Soga Y, Spijkervet FK, Tissing WJ, Epstein JB, Elad S, Lalla RV (2013) Systematic review of cytokines and growth factors for the management of oral mucositis in cancer patients. Support Care Cancer 21(1): 343-355. doi:10.1007/s00520-012-1594-5

30. Jensen SB, Jarvis V, Zadik Y, Barasch A, Ariyawardana A, Hovan A, Yarom N, Lalla RV, Bowen J, Elad S (2013) Systematic review of miscellaneous agents for the management of oral mucositis in cancer patients. Support Care Cancer 21(11):3223-3232. doi:10.1007/ s00520-013-1884-6

31. Saunders DP, Epstein JB, Elad S, Allemano J, Bossi P, van de Wetering MD, Rao NG, Potting C, Cheng KK, Freidank A, Brennan MT, Bowen J, Dennis K, Lalla RV (2013) Systematic review of antimicrobials, mucosal coating agents, anesthetics, and analgesics for the management of oral mucositis in cancer patients. Support Care Cancer 21(11):3191-3207. doi:10.1007/s00520-0131871-y

32. Yarom N, Ariyawardana A, Hovan A, Barasch A, Jarvis V, Jensen SB, Zadik Y, Elad S, Bowen J, Lalla RV (2013) Systematic review of natural agents for the management of oral mucositis in cancer patients. Support Care Cancer 21(11):3209-3221. doi:10.1007/s00520$013-1869-5$

33. McGuire DB, Fulton JS, Park J, Brown CG, Correa ME, Eilers J, Elad S, Gibson F, Oberle-Edwards LK, Bowen J, Lalla RV (2013) Systematic review of basic oral care for the management of oral mucositis in cancer patients. Support Care Cancer 21(11):31653177. doi:10.1007/s00520-013-1942-0

34. Lalla RV, Bowen J, Barasch A, Elting L, Epstein J, Keefe DM, McGuire DB, Migliorati C, Nicolatou-Galitis O, Peterson DE, Raber-Durlacher JE, Sonis ST, Elad S (2014) MASCC/ISOO clinical practice guidelines for the management of mucositis secondary to cancer therapy. Cancer 120(10):1453-1461. doi:10.1002/cncr.28592

35. Elad S, Thierer T, Bitan M, Shapira MY, Meyerowitz C (2008) A decision analysis: the dental management of patients prior to hematology cytotoxic therapy or hematopoietic stem cell transplantation. Oral Oncol 44(1):37-42. doi:10.1016/j.oraloncology.2006.12.006

36. Elad S, Garfunkel AA, Or R, Michaeli E, Shapira MY, Galili D (2003) Time limitations and the challenge of providing infectionpreventing dental care to hematopoietic stem-cell transplantation patients. Support Care Cancer 11(10):674-677. doi:10.1007/ s00520-003-0499-8

37. Durey K, Patterson H, Gordon K (2009) Dental assessment prior to stem cell transplant: treatment need and barriers to care. Br Dent J 206(9):E19. doi:10.1038/sj.bdj.2009.304, discussion 478-479

38. Zadik Y, Yarom N, Elad S (2012) Orofacial Neuropathy and Pain in Cancer Patients. In: Raffa R, Langford R, JV. PJ, Porreca F, Tallarida R (eds) Chemotherapy Induced Neuropathic Pain CRC press, pp 95-108 
39. Elad S, Raber-Durlacher J, Shapira MY (2010) Oral complications of hematopoietic stem cell transplantation. In: Epstein J (ed) Davies A. Oral complications of cancer and its management Oxford University Press, New York, pp 129-140

40. Kashiwazaki H, Matsushita T, Sugita J, Shigematsu A, Kasashi K, Yamazaki Y, Kanehira T, Yamamoto S, Kondo T, Endo T, Tanaka J, Hashino S, Nishio M, Imamura M, Kitagawa Y, Inoue N (2012) Professional oral health care reduces oral mucositis and febrile neutropenia in patients treated with allogeneic bone marrow transplantation. Support Care Cancer 20(2):367-373. doi:10.1007/s00520-0111116-x

41. Yamagata K, Arai C, Sasaki H, Takeuchi Y, Onizawa K, Yanagawa T, Ishibashi N, Karube R, Shinozuka K, Hasegawa Y, Chiba S, Bukawa $H$ (2012) The effect of oral management on the severity of oral mucositis during hematopoietic SCT. Bone Marrow Transplant 47(5):725-730. doi:10.1038/bmt.2011.171

42. Peterson DE, Overholser CD (1981) Increased morbidity associated with oral infection in patients with acute nonlymphocytic leukemia. Oral Surg Oral Med Oral Pathol 51(4):390-393

43. Greenberg MS, Cohen SG, McKitrick JC, Cassileth PA (1982) The oral flor as a source of septicemia in patients with acute leukemia. Oral Surg Oral Med Oral Pathol 53(1):32-36

44. Raber-Durlacher JE, Laheij AM, Epstein JB, Epstein M, Geerligs GM, Wolffe GN, Blijlevens NM, Donnelly JP (2013) Periodontal status and bacteremia with oral viridans streptococci and coagulase negative staphylococci in allogeneic hematopoietic stem cell transplantation recipients: a prospective observational study. Support Care Cancer 21(6):1621-1627. doi:10.1007/s00520-012-1706-2

45. Ruescher TJ, Sodeifi A, Scrivani SJ, Kaban LB, Sonis ST (1998) The impact of mucositis on alpha-hemolytic streptococcal infection in patients undergoing autologous bone marrow transplantation for hematologic malignancies. Cancer 82(11):2275-2281. doi:10.1002/ (SICI)1097-0142(19980601)82:11<2275::AID-CNCR25>3.0. $\mathrm{CO} ; 2-\mathrm{Q}$

46. Qutob AF, Allen G, Gue S, Revesz T, Logan RM, Keefe D (2013) Implementation of a hospital oral care protocol and recording of oral mucositis in children receiving cancer treatment: a retrospective and a prospective study. Support Care Cancer 21(4):1113-1120. doi:10. 1007/s00520-012-1633-2

47. Newbrun E (2001) Topical fluorides in caries prevention and management: a North American perspective. J Dent Educ 65(10):10781083

48. Ransier A, Epstein JB, Lunn R, Spinelli J (1995) A combined analysis of a toothbrush, foam brush, and a chlorhexidine-soaked foam brush in maintaining oral hygiene. Cancer Nurs 18(5):393-396

49. Sambunjak D, Nickerson JW, Poklepovic T, Johnson TM, Imai P, Tugwell P, Worthington HV (2011) Flossing for the management of periodontal diseases and dental caries in adults. Cochrane Database Syst Rev 12, CD008829. doi:10. 1002/14651858.CD008829.pub2

50. . http://www.gsk-dentalprofessionals.co.uk/product.aspx?parent= corsodyl treatment\&id=cor_original_mouthwash. Accessed on Dec. 2012

51. Hoffmann T, Bruhn G, Richter S, Netuschil L, Brecx M (2001) Clinical controlled study on plaque and gingivitis reduction under long-term use of low-dose chlorhexidine solutions in a population exhibiting good oral hygiene. Clin Oral Investig 5(2):89-95

52. Axelsson P, Lindhe J (1987) Efficacy of mouthrinses in inhibiting dental plaque and gingivitis in man. J Clin Periodontol 14(4):205-212

53. Van Strydonck DA, Timmerman MF, van der Velden U, van der Weijden GA (2005) Plaque inhibition of two commercially available chlorhexidine mouthrinses. J Clin Periodontol 32(3):305-309. doi: 10.1111/j.1600-051X.2005.00681.x

54. Van Strydonck DA, Slot DE, Van der Velden U, Van der Weijden F (2012) Effect of a chlorhexidine mouthrinse on plaque, gingival inflammation and staining in gingivitis patients: a systematic review.
J Clin Periodontol 39(11):1042-1055. doi:10.1111/j.1600-051X. 2012.01883.x

55. Addy M (2008) Oral hygiene products: potential for harm to oral and systemic health? Periodontol 2000(48):54-65. doi:10.1111/j.16000757.2008.00253.x

56. de Souza RF, de Freitas Oliveira Paranhos H, Lovato da Silva CH, Abu-Naba'a L, Fedorowicz Z, Gurgan CA (2009) Interventions for cleaning dentures in adults. Cochrane Database Syst Rev 4, CD007395. doi:10.1002/14651858.CD007395.pub2

57. Elad S, Wexler A, Garfunkel AA, Shapira MY, Bitan M, Or R (2006) Oral candidiasis prevention in transplantation patients: a comparative study. Clin Transplant 20(3):318-324. doi:10.1111/j.1399-0012. 2005.00484.x

58. Raber-Durlacher JE, Elad S, Barasch A (2010) Oral mucositis. Oral Oncol 46(6):452-456. doi:10.1016/j.oraloncology.2010.03.012

59. Sonis ST (2007) Pathobiology of oral mucositis: novel insights and opportunities. J Support Oncol 5(9 Suppl 4):3-11

60. Sonis ST (2011) Oral mucositis. Anticancer Drugs 22(7):607-612. doi:10.1097/CAD.0b013e3283462086

61. Benoliel R, Epstein J, Eliav E, Jurevic R, Elad S (2007) Orofacial pain in cancer: part I-mechanisms. J Dent Res 86(6):491-505

62. Epstein JB, Elad S, Eliav E, Jurevic R, Benoliel R (2007) Orofacial pain in cancer: part II-clinical perspectives and management. J Dent Res 86(6):506-518

63. Parulekar W, Mackenzie R, Bjarnason G, Jordan RC (1998) Scoring oral mucositis. Oral Oncol 34(1):63-71

64. Barasch A, Elad S, Altman A, Damato K, Epstein J (2006) Antimicrobials, mucosal coating agents, anesthetics, analgesics, and nutritional supplements for alimentary tract mucositis. Support Care Cancer 14(6):528-532. doi:10.1007/s00520-006-0066-1

65. Boer CC, Correa ME, Miranda EC, de Souza CA (2010) Taste disorders and oral evaluation in patients undergoing allogeneic hematopoietic SCT. Bone Marrow Transplant 45(4):705-711. doi:10. 1038/bmt.2009.237

66. Epstein JB, Barasch A (2010) Taste disorders in cancer patients: pathogenesis, and approach to assessment and management. Oral Oncol 46(2):77-81. doi:10.1016/j.oraloncology.2009.11.008

67. Stiff P (2001) Mucositis associated with stem cell transplantation: current status and innovative approaches to management. Bone Marrow Transplant 27(Suppl 2):S3-S11. doi:10.1038/sj.bmt. 1702863

68. Mohty M, Apperley JF (2010) Long-term physiological side effects after allogeneic bone marrow transplantation. Hematology Am Soc Hematol Educ Program 2010:229-236. doi:10.1182/asheducation2010.1.229

69. Schubert MM, Correa ME (2008) Oral graft-versus-host disease. Dent Clin North Am 52(1):79-109. doi:10.1016/j.cden.2007.10. 004, viii-ix

70. Strietzel FP, Lafaurie GI, Mendoza GR, Alajbeg I, Pejda S, Vuletic L, Mantilla R, Falcao DP, Leal SC, Bezerra AC, Tran SD, Menard HA, Kimoto S, Pan S, Martin-Granizo RA, Lozano ML, Zunt SL, Krushinski CA, Melilli D, Campisi G, Paderni C, Dolce S, Yepes JF, Lindh L, Koray M, Mumcu G, Elad S, Zeevi I, Barrios BC, Lopez Sanchez RM, Beiski BZ, Wolff A, Konttinen YT (2011) Efficacy and safety of an intraoral electrostimulation device for xerostomia relief: a multicenter, randomized trial. Arthritis Rheum 63(1):180-190. doi: 10.1002/art.27766

71. Castellarin P, Stevenson K, Biasotto M, Yuan A, Woo SB, Treister NS (2012) Extensive dental caries in patients with oral chronic graftversus-host disease. Biol Blood Marrow Transplant 18(10):15731579. doi:10.1016/j.bbmt.2012.04.009

72. Ship JA, McCutcheon JA, Spivakovsky S, Kerr AR (2007) Safety and effectiveness of topical dry mouth products containing olive oil, betaine, and xylitol in reducing xerostomia for polypharmacyinduced dry mouth. J Oral Rehabil 34(10):724-732. doi:10.1111/j. 1365-2842.2006.01718.x 
73. Shen P, Manton DJ, Cochrane NJ, Walker GD, Yuan Y, Reynolds C, Reynolds EC (2011) Effect of added calcium phosphate on enamel remineralization by fluoride in a randomized controlled in situ trial. $\mathrm{J}$ Dent 39(7):518-525. doi:10.1016/j.jdent.2011.05.002

74. Greinix HT, Volc-Platzer B, Rabitsch W, Gmeinhart B, GuevaraPineda C, Kalhs P, Krutmann J, Honigsmann H, Ciovica M, Knobler RM (1998) Successful use of extracorporeal photochemotherapy in the treatment of severe acute and chronic graft-versus-host disease. Blood 92(9):3098-3104

75. Treister N, Duncan C, Cutler C, Lehmann L (2012) How we treat oral chronic graft-versus-host disease. Blood 120(17):3407-3418. doi:10. 1182/blood-2012-05-393389

76. Mawardi H, Elad S, Correa ME, Stevenson K, Woo SB, Almazrooa S, Haddad R, Antin JH, Soiffer R, Treister N (2011) Oral epithelial dysplasia and squamous cell carcinoma following allogeneic hematopoietic stem cell transplantation: clinical presentation and treatment outcomes. Bone Marrow Transplant 46(6):884-891. doi:10.1038/ bmt.2011.77

77. Sivolella S, Lumachi F, Stellini E, Favero L (2013) Denosumab and anti-angiogenetic drug-related osteonecrosis of the jaw: an uncommon but potentially severe disease. Anticancer Res 33(5):1793-1797

78. Ruggiero SL, Dodson TB, Fantasia J, Goodday R, Aghaloo T, Mehrotra B, O'Ryan F (2014) American Association of Oral and Maxillofacial Surgeons Position Paper on Medication-Related Osteonecrosis of the Jaw-2014 Update. J Oral Maxillofac Surg. doi:10.1016/j.joms.2014.04.031

79. Chaushu G, Bercovici M, Dori S, Waller A, Taicher S, Kronenberg J, Talmi YP (2000) Salivary flow and its relation with oral symptoms in terminally ill patients. Cancer 88 (5): 984-987. doi:10.1002/(SICI)1097-0142(20000301) $88: 5<984:: A I D-C N C R 6>3.0 . C O ; 2-0$ [pii]
80. Chaushu G, Itzkovitz-Chaushu S, Yefenof E, Slavin S, Or R, Garfunkel AA (1995) A longitudinal follow-up of salivary secretion in bone marrow transplant patients. Oral Surg Oral Med Oral Pathol Oral Radiol Endod 79(2):164-169

81. Laaksonen M, Ramseier AM, Rovo A, Jensen SB, Raber-Durlacher JE, Zitzmann NU, Waltimo T (2011) Longitudinal assessment of hematopoietic stem cell transplantation and hyposalivation. J Dent Res 90(10):1177-1182. doi:10.1177/0022034511414156

82. Glenny AM, Gibson F, Auld E, Coulson S, Clarkson JE, Craig JV, Eden OB, Khalid T, Worthington HV, Pizer B (2010) The development of evidence-based guidelines on mouth care for children, teenagers and young adults treated for cancer. Eur J Cancer 46(8):13991412. doi:10.1016/j.ejca.2010.01.023

83. Council on Clinical Affairs (2013) Guideline on dental management of pediatric patients receiving chemotherapy, hematopoietic cell transplantation, and/or radiation. Pediatr Dent 35(5):E185-193

84. US Food and Drug Administration (2014) FDA Drug Safety Communication: FDA recommends not using lidocaine to treat teething pain and requires new Boxed Warning. http://www.fda. gov/Drugs/DrugSafety/ucm402240.htm Accessed Jul. 2014

85. Bagesund M, Richter S, Agren B, Ringden O, Dahllof G (2000) Scintigraphic study of the major salivary glands in pediatric bone marrow transplant recipients. Bone Marrow Transplant 26(7):775779. doi:10.1038/sj.bmt. 1702556

86. American Academy of Pediatric Dentistry Clinical Affairs Committee, American Academy of Pediatric Dentistry Council on Clinical Affairs, (2005) Guideline on dental management of pediatric patients receiving chemotherapy, hematopoietic cell transplantation, and/or radiation. Pediatr Dent 27(7 Suppl): $170-175$ 